\title{
Play Preference and Pretend Play Skills between Typically Developed Children and Autism
}

\author{
Jayachandran Vetrayan ${ }^{1 *}$, Sharif Umar Haiyuddin Mohamed Nazir ${ }^{1}$, \\ Smily Jesu Priya Victor Paulraj ${ }^{1}$ \\ ${ }^{1}$ Universiti Teknologi MARA(UiTM), Faculty of Health Science, Puncak Alam, 42300, Malaysia
}

\begin{abstract}
Pretend play emerged at the age of 18 months in children. The imagination of children creates new play ideas it has incorporated into their play. But Autism children find difficulty in play. Hence, this study aimed to find the different types of pretend and preference play among autistic and typical children. The total sample of 40 is divided into 20 each group respectively. Data analyzed by using Chi-Square result in the significant difference between the pretend play and play preference $X^{2}=42.81$ $(p=0.05$ and $p=0.01)$. Future study needs to examine with larger samples.
\end{abstract}

(C) 2016. The Authors. Published for AMER ABRA by e-International Publishing House, Ltd., UK. This is an open access article under the CC BY-NC-ND license (http://creativecommons.org/licenses/by-nc-nd/4.0/).

Peer-review under responsibility of AMER (Association of Malaysian Environment-Behaviour Researchers), ABRA (Association of Behavioural Researchers on Asians) and CE-Bs (Centre for Environment-Behaviour Studies), Faculty of Architecture, Planning \& Surveying, Universiti Teknologi MARA, Malaysia.

Keywords: Pretend Play; Play Preferences; Autism; Typically Developed children.

\section{Introduction}

Pretend play is one of the components of play and emerges by the age of 18 months in typically developed children. The term "pretend play" as established by Stagnitti and Unsworth (2000) encompasses both symbolic play and conventional-imaginative play. A conventional-imaginative play defined as "play in which a child plays with commercially available toys and relates the toys to each other". Symbolic play can define as "play in which a child plays with unstructured objects and connects these objects to each other while imposing meaning on them" (Stagnitti \& Unsworth, 2000; Pfeifer, Queiroz, F. Santos, \& Stagnitti, 2011). Although this type of play can come quite naturally to typically developed children, children suffering from disabilities are often at a particular disadvantage when engaging in pretend play.

* Jayachandran Vetrayan. Tel.: 6032584397; fax: 6032584499.

E-mail address: jayachandran@puncakalam.uitm.edu.my

2398-4287 @ 2016. The Authors. Published for AMER ABRA by e-International Publishing House, Ltd., UK. This is an open access article under the CC BY-NC-ND license (http://creativecommons.org/licenses/by-nc-nd/4.0/).

Peer-review under responsibility of AMER (Association of Malaysian Environment-Behaviour Researchers), ABRA (Association of Behavioural Researchers on Asians) and CE-Bs (Centre for Environment-Behaviour Studies), Faculty of Architecture, Planning \& Surveying, Universiti Teknologi MARA, Malaysia.

DOI: http://dx.doi.org/10.21834/e-bpj.v1i3.345 


\subsection{Literature review}

According to Wyman, Rakoczy and Tomasello (2009) identify the multiple pretend play for three years old child especially the identities of objects. The researchers measured these 3-year-olds' pretend to play by observing their creative and inferential pretend actions. This research stated that the three old children could understand the pretend object identify in early life. "It raises interesting possibilities that children's games of joint pretend play might equip them with the fundamentals of a conceptual framework that they will later come to elaborate, and that will, in turn, allow them to participate in adult institutional life (Kalish, 2005; Rakoczy, 2007; Walton, 1990; Wyman, Rakoczy \& Tomasello, 2009)". Pretend play plays a very significant role in a child's overall development and prepares them for the roles that are expected by society.

Typically grown children may differ from children with Autism in how they interact during play sessions. The majority of children with autism will experience greater difficulties engaging in play with their peers as they focused on their world and their play behavior is considered "abnormal" compared to the norm. Dominguez, Ziviani, and Rodger (2006) examined the play engagement and play object preferences between autism and typically developing children. The study showed there was no difference between the groups in symbolic play. Early studies also supported the symbolic play was no significant change between two group (Lewis and Boucher, 1998; Libby et al., 1998; Ungerer \& Sigman, 1981; Baron-Cohen, 1987). Following results may be due to the restrictions of the child's play as they were observed playing alone, which leads to a limited production of a symbolic play, and which coincides with the social environment and play alone nature of the child during evaluation time. The limited symbolic play does not affect the functional and early behavior play for children with autism during the initial assessment (Dominguez, Ziviani \& Rodgers, 2006). Whereby, finding shows there was the difference in playing object preference amongst the healthy children and autism. "Children with autism played significantly more with gross motor toys, the Thomas the Tank Engine train set, infant toys, donning the accessories kit, action figures and plastic animal toys. They play significantly less frequently with construction toys, dolls, and house toys (Dominguez, Ziviani \& Rodgers, 2006)". The authors mentioned that autism children preference play object was select from the media. Because autistic children more spend time in watching televisions and computers but less time spends in peer interaction and communication others (Dominguez, Ziviani \& Rodgers, 2006).

According to Uren and Stagnitti (2009) examined the relationship between play skills, functional school activities and social proficiency. The author included primary school children with the age range of 5 to 7 years to explore the play skills and social competence by using Child-Initiated Pretend Play Assessment (ChiPPA). The result showed the pretend play connected to the child capability especially in the participation skills and social competency. According to the Uren \& Stagnitti, 2009 stated the assessment score of the ChiPPA were used with the other scales to examine the functional school activities and social skill. The ChiPPA's had a concurrent validity to measure the pretend play. Besides that, another study was confirming the construct validity for ChiPPA's (Swindells and Stagnitti, 2006).

Although children with Autism face difficulties in initiating pretend play, they can be taught to improve the pretend play through constant exposure and rehearsal sessions. There are various interventions given to children with autism to regain their ability to pretend play. In a study conducted by Murdock and Hobbs (2011), used the Picture Me Playing intervention to enhance the pretend play skills in preschool autistic and typically developed children. According to Smily et al., (2015) stated the Imitation learning for ten weeks of intervention in children with autism and showed improvement in imitation play skills. This imitation ability will also improve the pretend play among children with autism. And also finding from Jayachandran et al., (2015) stated there is a great relationship between imitation and functional activity among children with autism. These are the possible recent studies on autism and playability. But the limited study has conducted on different types of pretend play and play preference among autistic and typically developing children. Therefore, the purpose of the study aimed to find the various kinds of pretend play and play choice among autistic and typically developed children. The research objectives of i) to find the different types of pretend play styles among autistic and typically developed children ii) to determine the various types of play preferences among autistic and typically developed children. 


\section{Methodology}

\subsection{Sample}

This study is a cross-sectional exploratory research which employs the correlational research design as its instrumentation. The sample for this study is a convenience sample consisting of 40 children from either child community rehabilitation centers or private pre-schools and some children from friends or family relatives. The samples took from three different states in Malaysia - Selangor, Kedah, and Penang. The 40 children were dividing into two groups, each consisting of 20 children who categorized as 'typically developed children' and 'children with Autism' Inclusion criteria are as follows; i) children aged four years to 7 years 11 months of age, ii) children who diagnosed with Autism, and iii) typically developed children. Exclusion criteria: i) children under the age of 4 years or beyond seven years 11 months, ii) children suffering from severe physical disabilities, iii) children born with developmental disorders such as Down Syndrome, Rett Syndrome, etc., and iv) Visually impaired children.

\subsection{Instruments}

The researcher used two standardized assessments to carry out this study. "The Child-Initiated Pretend Play Assessment (ChiPPA) which is a play-based assessment to examine the pretend play. ChiPPA is a standardized assessment that measures the ability of 3 to 7 -year-old children to initiate and engage in spontaneous pretend play over the course of 30 minutes (for 4 - to 7-year-olds) or 18 minutes (for three-year-olds) period (Stagnitti, 2007,2004; Uren \& Stagnitti, 2009)". This assessment administered one by one and free for any distraction and noise.

The second assessment to evaluate a child's play preference is the Children's Play Behaviour Questionnaire. It consists of 19 questions and takes roughly around 25 minutes to administer (Pfeifer, Terra, Ferreira dos Santos, Stagnitti, Panúncio-Pinto, 2011). This questionnaire can be self-administered by the child or proxy by caregivers if their level of literacy is low.

\subsection{Data Collection Procedure}

Ethics approval obtained from the Ethics Committee Faculty of Health Sciences, Universiti Teknologi MARA (UiTM), Puncak Alam Campus. Private pre-school and child community rehabilitation centers were approved by their respective. All ethical procedures adhered to maintain confidentiality.

The ChiPPA assessment was carried out in a separate room provided by the pre-schools or child rehabilitation centers. The next part of the assessment, which is the Children's Play Behaviour Questionnaire, involves asking several questions which consist of 19 questions. From the 19 questions, three questions are highlighted which are: play partner preferences, places to play preferences, and toys and play activity preferences.

\subsection{Data Analysis}

The Chi-Square test was used to examine the correlation between play style among Typically Developed Children and Children with Autism.

\section{Results}

Table.1. Demographic data of the samples

\begin{tabular}{llll}
\hline & & Frequency & Percentage \\
\hline Gender & Male & 27 & $67.5 \%$ \\
& Female & 13 & $32.5 \%$ \\
\hline
\end{tabular}




\begin{tabular}{llll}
\hline Race & Malay & 38 & $95.0 \%$ \\
& Chinese & 2 & $5.0 \%$ \\
Sample & Autism child & 20 & $50 \%$ \\
& Typical child & 20 & $50 \%$ \\
\hline
\end{tabular}

Table 1 shows the demographic data of the samples used in the study. Out of the 40 subjects used in this study, $27(67.5 \%)$ are male children and $13(32.5 \%)$ are female children. The majority of the children were Malays representing $38(95 \%)$ of the total subjects, with children of Chinese ethnicity only representing $2(5 \%)$ of the entire subjects.

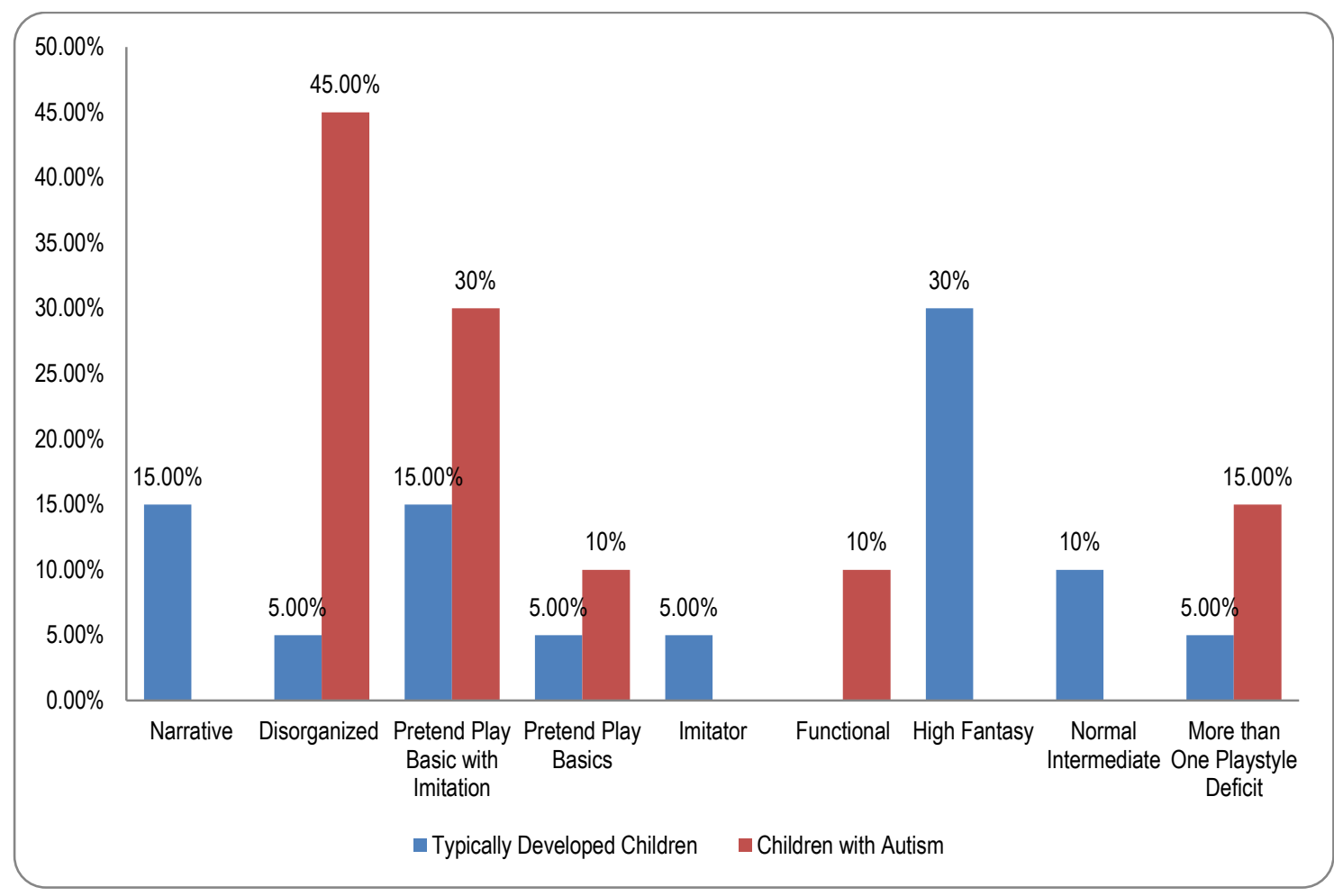

Figure1: Play styles of Typically Developed Children and Children with Autism

Figure 1 showed the different play style present among the typical and children with autism. In typically developing children $75 \%$ of the sample has abnormal play style. In that five deficit play styles were found which were "Imitator" play style (5\%), "High Fantasy" play style (30\%), "Pretend Play Basics" play style (5\%), "Pretend Play Basics with Imitation" play style (15\%), the "Disorganized" play style (5\%) and $25 \%$ of the sample have the Normal play style is Narrative play style $15 \%$. In children with autism, $100 \%$ of the sample shows the abnormal play style which was "Disorganized" play style (45\%), "Pretend Play Basics with Imitation" play style (30\%), "Pretend Play Basics" play style (10\%), and "Functional Player" play style (10\%).

In Table 2, the Chi-square value exceeded the threshold value of $p=0.05$ and $p=0.01$ (three degrees of freedom). Therefore, there is a statistically significant difference in playstyles frequencies at $p=0.05$ and $p=0.01$ between typically developed and children with Autism. 
Table 2: Correlation between play style among Typically Developed Children and Children with Autism.

\begin{tabular}{|c|c|c|c|c|c|}
\hline Play Style Type & 0 & $\bar{E}$ & $(\mathrm{O}-\mathrm{E})$ & $(O-E)^{2}$ & $\frac{(0-E)^{2}}{E}$ \\
\hline $\begin{array}{l}\text { Normal Playstyle (Normal } \\
\text { Children) }\end{array}$ & 5 & 16 & -11 & 121 & 7.56 \\
\hline $\begin{array}{l}\text { Abnormal Playstyle (Normal } \\
\text { Children) }\end{array}$ & 15 & 4 & 11 & 121 & 30.25 \\
\hline $\begin{array}{l}\text { Normal Playstyle (Children with } \\
\text { Autism) }\end{array}$ & 0 & 4 & -4 & 16 & 4 \\
\hline $\begin{array}{l}\text { Abnormal Playstyle (Children } \\
\text { with Autism) }\end{array}$ & 20 & 16 & 4 & 16 & 1 \\
\hline
\end{tabular}

In Table 3, shows the level of preferences among person, place, and toys of children with autism and typically developed children. Both groups are preferred same types of play partners, play place and play toys.

Table 3: Preferences patterns of play partners play place and play toys among two groups

\begin{tabular}{|c|c|c|c|c|c|c|}
\hline \multirow{2}{*}{$\begin{array}{l}\text { Level of } \\
\text { Preferred }\end{array}$} & \multicolumn{3}{|c|}{ Typically developed children $(\mathrm{N}=20)$} & \multicolumn{3}{|c|}{ Children with Autism $(\mathrm{N}=20)$} \\
\hline & Play Partners & Play Place & Play toys & Play Partners & Play Place & Play toys \\
\hline \multirow[t]{4}{*}{ Most preferred } & Siblings & Inside home & Computer & Parents & Inside home & Computer \\
\hline & Classmate & School & games & Siblings & School & games \\
\hline & Boys and Girls & Yard & Video games & Others & Yard & Miniature cars \\
\hline & & & Dolls & & & Video games \\
\hline \multirow[t]{3}{*}{ Preferred } & Father & Inside home & Run and catch & Siblings & Inside home & Run and Catch \\
\hline & Mother & School & Draw & Mother & School & Balls \\
\hline & & Yard & Balls & Parents & Yard & $\begin{array}{l}\text { Computer } \\
\text { Games }\end{array}$ \\
\hline \multirow{4}{*}{$\begin{array}{l}\text { Least } \\
\text { preferred }\end{array}$} & Same gender & Square & Who got the & Classmates & Square & Elastic \\
\hline & Neighbour's & Club & & Same gender & Club & Draw \\
\hline & & Neighbour's & Marbles & Boys and girls & Neighbour's & Dollhouse \\
\hline & & House & Skate & & House & \\
\hline
\end{tabular}

Play partner preferences between the two groups. There were some significant similarities between these two groups about preference (most preferred, preferred, and least preferred) for play partners. For the most preferred category, typically developed children showed most preference to playing with siblings, classmates and boys and girls, while children with Autism mostly preferred to play with parents, siblings, and others. It seems that siblings were their choice of play partners in both groups. Typically developed children preferred to play with their fathers, mothers or both parents, while children with Autism preferred to play with their siblings, mother and parents. Both groups seemed to have a preference to play with their mothers or their parents. For the least preferred category, typically developed children will be least likely to play with children of the same gender and with neighbors. For children with Autism, their least preferred play partners seem to be with their classmates, boys and girls, and children of the same gender. Both groups seemed less likely to play with children of the same gender.

Play place between typically developed children and children with Autism. It appears that both groups mostly preferred to play 'inside the home, school, and the yard.' Inside the home is both group's most preferred choice of location to play. Typically developed children preferred to play in school while children with Autism preferred to play outside in the yard. Both groups least preferred the square, club and neighbor's house as their choice of places to play. Typically developed children least preferred to play at the square, while children with Autism least preferred neighbor's house and clubs. 
Play toys between typically developed children and children with Autism. There were similarities between the groups about most preferred toys were "computer games, Video games, but children with autism most preferred miniature cars". Preferred toys for both groups are balls. And least preferred toys for normal children were marbles and skate but for autism children least preferred doll house and draw.

\section{Discussion}

Among the 40 children that have participated in this study, the majority i.e. 38 were of Malay ethnicity (95\%), while the remaining two children were of Chinese ethnicity (5\%). The majority of the children in this study played with the toys that provided for them by the ChiPPA while a few of them requested other toys to bring into the play style study.

According to first research question to answer there are different types of pretend play style among both groups by using ChiPPA. The result shows there were different types of pretend play style between groups. Spontaneous pretend play of typically developing children were five children ( $25 \%$ of the sample) showed typical playstyles. Three children (15\% of the sample) showed a pure typical playstyle, identified by good scores in elaborate pretend play actions (PEPA) in both play sessions, ability to substitute objects and a low NIA. However, out of the three children who showed typical playstyles, one of the children had a PEPA conventional-imaginative score which indicates a play delay. Even though that child's PEPA conventional-imaginative score is below age range, the child was still considered as having a typical playstyle due to the observation is seen when that child was playing which indicated that the child was prone to a typical playstyle. In typical play style, one style was noted which was the "Narrative Based Playstyle." The remaining two children, who make up the $10 \%$ of the total $25 \%$, displayed "Normal Intermediate Playstyle" that categorized by the child having a mixture of normal and abnormal playstyle. The normal intermediate playstyle which was noted were the "Narrative Based and High Fantasy" and "Engineer Based and Pretend Play Basics." However, the majority of the sample i.e. 15 children ( $75 \%$ of the sample), showed playstyles with deficits in pretend play. Five deficit playstyles were found which were "Imitator" playstyle (5\%), "High Fantasy" playstyle (30\%), "Pretend Play Basics" playstyle (5\%), "Pretend Play Basics with Imitation" playstyle (15\%), and the "Disorganized" playstyle (5\%). From the 15 children, three children (15\%) showed a combination of two abnormal playstyles, which are "Imitator and High Fantasy" playstyle, "Functional and High Fantasy" playstyle, and "High Fantasy and Pretend Play Basics with Imitation" playstyle.

The spontaneous pretend play of all 20 autistic children (100\% of the sample) showed abnormal playstyles. Four deficits of playstyles found which were "Disorganized" playstyle (45\%), "Pretend Play Basics with Imitation" playstyle (30\%), "Pretend Play Basics" playstyle (10\%), and "Functional Player" playstyle (10\%). One child showed a combination of two abnormal playstyles which is the "Disorganized and Pretend Play Basics" playstyle (5\%). Based on the result there was difference play style between normal and autism. The children who got the low score they unable to perform the play. Early study also stated that the child who got the low score they unable to performance the play and tough to adapt with their peer interaction Stagnitti, (2007) as quoted by Pfeifer Pacciulio, dos Santos, dos Santos and Stagnitti (2011).

Both groups of children yielded statistical significance using the Chi-Square test which showed that the chisquare value exceeded the threshold value of $p=0.05$ which is a $95 \%$ confidence interval and that the data sample scores were not due to chance, but there is a real difference between them. There are possible reasons for the majority of typically developed children to have shown abnormal playstyles as opposed to regular playstyles. One of the possible explanations could be that the child may have underperformed in the presence of an examiner. They may appear shy and timid towards the inspector who leads to them unable to come up with play ideas. It may also be that they feel that they watched by an unfamiliar face who is examining them. It also leads to them trying to perform as expected by the examiner who will mask their full potential in pretend play skills.

The next research question that answered in this study is if there are any changes in play preferences of children with Autism compared to typically developed children. Regarding play partner preferences, it seems that there are slight similarities between both groups regarding their most preferred play partners. Typically developed children 
mostly preferred to play with their siblings while children with Autism mostly preferred to play with both mother and father, with siblings being their second most preferable partners to play. Siblings may be the most preferred play partners for both groups because the social development occurred in the family and also to interact easily with the family members (Pfeifer, Terra, Ferreira dos Santos, Stagnitti, \& Panúncio-Pinto, 2011). "The relationship between siblings includes elements of direct reciprocity, in which siblings actively shape the life of each other that contributes to the ability to play with other partners (Lobato, 1990; Pfeifer, Terra, Ferreira dos Santos, Stagnitti, \& PanúncioPinto, 2011)." Children with Autism are more comfortable interacting with their parents as they feel safe in their presence and constant care.

There were significant similarities between both groups about preferred places to play. Both groups most preferred places to play were inside the home, in the school, and outside the yard of their home. It is likely to assume that children with Autism will select the place to play with safety and under the supervision of the adults. The study identified that school considered as a significant place for children since it provides safety, enjoyment, feeling, friend's interaction, develop a partnership, entrainments, and independent play. However, it is surprising that Brazil typically developed children mostly preferred to play in these types of places such as open places in streets and roads because the children like to play with freedom. But the play areas are cleans and very unstructured The reasoning for why typically developed children preferred to play in places that offer protection and safety may be due to the parent's concerns regarding the dangers of playing outside the security zone of the home as cases of children kidnapped by criminals are running rampant which threatens the safety of their children (Pfeifer, Terra, Ferreira dos Santos, Stagnitti, \& Panúncio-Pinto, 2011).

In regards to toys, both groups seemed to have similar high preferences to computer games and video games. It has supported by Pfeifer, Terra, Ferreira dos Santos, Stagnitti, \& Panúncio-Pinto, (2011), play with computer games has increased recent years and child stay in front of the monitor without socially and physically connected and distended from a real world. Based on the identification of new direction from this study, suggested the further research were conduct on why the typically developed children have abnormal play style compared with peer groups and cultural variation also needs to address. Influence of contextual environment on the play preference in both typical and children with autism also need to study with the overcoming of some the limitation of this study like small sample size and play intervention to overcome the abnormal play style.

\section{Conclusion}

In conclusion, this study started that the majority of children with Autism will display abnormal playstyles as compared with their typically developed peers. However, typically developed peers also showed a high percentage of abnormal playstyles. There is also a significant difference between the pretend play style between children with autism and typically developed children, and there is no major difference in the play preference of partner, place, and toys for play among the two groups.

\section{Acknowledgement}

This study supported by Research Management Center (RMC) of Universiti Teknologi MARA and funded by a Fundamental Research Grant Scheme (FRGS) 600-RMI FRGS 5/3 (27/2014), Ministry of Higher Education (MOHE) in Malaysia.

\section{References}

Baron-Cohen, Simon. 1987. "Autism and Symbolic Play." British Journal of Developmental Psychology 5:139-48.

Dominguez, A., Ziviani, J., \& Rodger, S. (2006). Play behaviours and play object preferences of young children with autistic disorder in a clinical play environment. Autism, 10(1), 53-69. 
Vetrayan. J., Mohd zin, M.F., Paulraj S.J.V.P (2015) Relationship between visual perception and imitation in school function among autism. Procedia Social and Behavioural Science, 202, 67- 75.

Kalish. C., (2005) Becoming status conscious: children appreciation of social reality. Philosophical exploration. 8(3), 245- 263.

Lewis, Vicky, and Jill Boucher. (1988). "Spontaneous, Instructed, and Elicited Play in Relatively Able Autistic Children." British Journal of Developmental Psychology, 6, 325-39.

Libby, Sarah, Stuart Powell, David Messer, and Rita Jordan. 1998. "Spontaneous Play in Children with Autism: A Reappraisal." Journal of Autism and Developmental Disorders 28:487-97.

Lobato, d.J. (1990). Brothers. Sisters, and special needs; Information and activities for helping young siblings of children with chronic illnesses and developmental disabilities.balti-more, md: Paul brookes Publishing Co.

Murdock, L. C., \& Hobbs, J. Q. (2011). Picture me playing: Increasing pretend play dialogue of children with Autism Spectrum Disorders. Journal Autism Developmental Disorders, 41, 870-878.

Pfeifer, L. I., Terra, L. N., Ferreira dos Santos, J. L., Stagnitti, K. E., \& Panúncio-Pinto, M. P. (2011). Play preference of children with ADHD and typically developing children in Brazil: A pilot study. Australian Occupational Therapy Journal, 58, 419-428.

Pfeifer, L.I., Pacciulio, A.M., Dos santos, C.A., Dos santos, J.L., Stagniti, K.E. (2011) Pretend play of children with cerebral palsy. Physical \& Occupational therapy in peadiatrics, 31 (4), $390-402$.

Pfeifer, L. I., Queiroz, M. A., F. Santos, J. L., \& Stagnitti, K. E. (2011). Cross-cultural adaptation and reliability of Child-Initiated Pretend Play Assessment (ChIPPA).Canadian Journal of Occupation Therapy, 78(3), 186-194.

Rakoczy, H. (2007). Play, games and the development of collective intentionality. New Directions in Child and Adolescent Development (Special issue on 'Conventionality') ,115, 53-68.

Smily, J.P.V., Ruwinah, A.K., \& Jayachandran, V (2015), Evaluation of Occupational Performance Imitation Approach (OPIA) on three Imitative Learning among Autism Spectrum Disorder, case series, Procedia - Social and Behavioral Sciences, 202, 56-58.

Stagnitti, K.E (2007). Child-initiated pretend play assessment (ChIPPA). Manual and Kit. Melbourne, Australia: Co-ordinates. Stagnitti, K.E, \& Unsworth, C. (2000). The Importance of Pretend Play in Child Development. An Occupational Therapy Perspective. British Journal of Occupational Therapy, 63(3),121-127.

Stagnitti, K.E, \& Unsworth, C. (2004). The test-retest reliability of the Child-Initiated Pretend Play Assessment. The American Journal of Occupational Therapy, 58(1), 93-99. Retrieved from http://ajot.aota.org

Swindells, D., \& Stagnitti, K. E. (2006). Pretend play and parents' view of social competence: The construct validity of the Child-Initiated Pretend Play Assessment. Australian Occupational Therapy Journal, 53, 314-324.

Ungerer, Judy A., and Marian Sigman. 1981. "Symbolic Play and Language Comprehension in Autistic Children." Journal of the American Academy of Child Psychiatry, 20,318-37.

Uren, N., \& Stagnitti, K. E. (2009). Pretend play, social competence and involvement in children aged 5-7 years: The concurrent validity of the Child-Initiated Pretend Play Assessment. Australian Occupational Therapy Journal, 56, 33-40.

Walton, K. (1990). Mimesis as make-believe. Cambridge, MA: Harvard University Press.

Wyman, E., Rakoczy, H., \& Tomasello, M. (2009). Young children understand multiple pretend identities in their object play. British Journal of Developmental Psychology, 27, 385-404. 